\title{
EXPERT SYSTEM OF NON-POLLUTION FEICHENG PEACH PRODUCTION IN CHINA
}

\author{
Ming Li, Yan'an Wang ", Lihui Wang, Zhiqiang Yan, Qingyan Yu \\ College of Life Science, Shandong Agricultural University, Taian, Shandong, China, 271018 \\ * Corresponding author, Address: College of Life Science, Shandong Agricultural University, \\ 61 Daizong Street, Tai'an, 271018, P. R. China, Tel: +86-538-8249144, Email: wyasdau@ \\ 126.com
}

Abstract: In order to promote standard Feicheng peaches production, based on long-term research and integrated achievements of many disciplines on Feicheng peach, following the standard of localization, characteristic and non-pollution, adopting the knowledge engineering, and using PAID (Platform for Agricultural Intelligence-system Development), the expert system of nonpollution Feicheng peach production has been developed. As the samples of knowledge representation, the model of water-saving irrigation and pattern of search list for differentiation between diseases and insect pests are discussed. Through application of the system, the users have acquired significant social and economic benefit.

Keywords: Feicheng peach (Prunus persica cv. Feicheng), non-pollution, expert system, knowledge representation

\section{INTRODUCTION}

Feicheng peach (Prunus persica cv. Feicheng), a kind of fruit mainly produced in Feicheng, Shandong province, China, is famous at home and abroad for big size, excellent taste and abundant nutrition, and praised as "the champion of peaches". Up to January, 2005, the city has 4,800 ha of Feicheng peaches as green food for grade A. In future, the city is going to enhance the informatization of Feicheng peach industry in order to drive marketization and promote industrialization. Agricultural expert system is a 
useful decision tool for growers and county extension faculty with standard cultivation.

Since the first agricultural expert system (PLANT/ds) was developed (Michalski et al., 1982), a lot of expert systems (ES) or decision support systems (DSS) on peach have been readily available and affordable, such as an expert system for the diagnosis of peach and nectarine disorders (Plant et al., 1989), a user friendly peach tree growth and yield simulation model for research and education (Allen and Dejong 2002), peach expert system (Wang et al., 2001). A literature search reveals no attempt in developing localized, characteristic and non-pollution expert system for peach. Also the existing diagnosis expert systems are lack of differentiation of diseases and insect pests. In order to promote the non-pollution Feicheng peaches production, from 2001 to 2005, the expert system of non-pollution Feicheng peach production was developed and applied in Feicheng city.

\section{SYSTEM DESIGN}

\subsection{Architecture}

The system architecture is designed according to existing conditions of demonstration districts and framework of PAID. The decision-making system of Feicheng peach production includes overall agronomic practices, such as decision-making for orchard selection, orchard plan, soil management methods, soil fertilizing methods, fertilizing dose rate, watersaving irrigation, methods of training and pruning, course of training and pruning, flower and fruit thinning, manual pollination and bagging technique, evaluation of quality traits of fresh fruits, differentiation between diseases and insect pests, diagnosis and control of infectious diseases, diagnosis and control of non-infectious diseases, morphological diagnosis of malnutrition, diagnosis and control of foliar nutrition, diagnosis and control of insect pests and so on.

\subsection{Knowledge representation}

Agronomic practice is not only calculating crop water requirements but it includes other issues which needs human judgment. Expert system technology can help in two ways: first, the mathematical models can be implemented using expert systems technique with the advantage of explaining to the user how the model calculates a certain quantity; second, 
the heuristic and symbolic knowledge which cannot be mathematically modeled is to be included easily. So, the mathematic model and production rule is applied in knowledge representation. The examples are following.

\subsubsection{Mathematic model}

The model of water-saving irrigation is expressed as the formula (1) reflecting the relationship of each parameter in the model (Xu, 1998):

$$
X=Y \times Q \times A \times P \times(B-R)
$$

where $X$ is net irrigation water $(\mathrm{kg} / \mathrm{ha}), \mathrm{Y}$ is irrigation $\operatorname{area}\left(\mathrm{m}^{2}\right), \mathrm{Q}$ is cover rate of tree canopy(\%), A is irrigation $\operatorname{depth}(\mathrm{m}), \mathrm{P}$ is soil bulk density, B is expected soil water content $(\%), \mathrm{R}$ is practical soil water content $(\%)$.

\subsubsection{Production rule}

Facing a kind of abnormal phenomenon, it is important to judge whether it is caused by diseases or insect pests scientifically and correctly; If it is a disease, then whether is it infectious or non-infectious one? If it is infectious disease, which kind of factor causes it? When it is non-infectious disease, which kind of pathogen causes it? In order to solve the problems, the model of diagnosis \& control of diseases and insect pests offers three diagnosis paths: in the first path, the users can carry out differentiation between diseases and insect pests at first, if it is a disease, then decide whether it is infectious or non-infectious, later enter related decision-making module to diagnosis; As the second path, the users can enter directly related decisionmaking for diagnosis \& control of infectious diseases, decision-making for diagnosis \& control of non-infectious diseases, decision-making for morphological diagnosis \& control of malnutrition, decision-making for diagnosis \& control of foliar nutrition, or decision-making for diagnosis \& control of insect pests to diagnose; In the third path, the users optionally can consult directly the integrated information querying system to query related content of diseases and insect pests if they know the causes of problem (Wang et al., 2005). In summary, the search list of differentiation between diseases and insect pests is made.

\section{SYSTEM IMPLEMENTATION}

Coming to editing of knowledge rules, referred to the CommonKADS methodology (Schreiber, Shi et al., translated, 2003), the knowledge rules are edited by template and formalized according to the request of PAID, which improves the efficiency of development. 


\section{SYSTEM APPLICATION}

This system has demonstrated and extended for more than 670 ha totally, the yield of Feicheng peaches increases by $8 \%-10 \%$, cost decreases by $10 \%-12 \%$, the rate of high-quality fruit increases by $15 \%-20 \%$, and $95 \%$ of fruit has reached the standard of non-pollution food. The ordinary users have been trained for about 5300 person-times, which acquires significant social and economic benefit.

\section{ACKNOWLEDGEMENTS}

The research was funded by Taian "The Tenth Five-year Plan" key project (2001003) and Shandong provincial key extention project in 2003 (2003129).

\section{REFERENCES}

Allen M.T., Dejong M.T. Using L-system to model carbon transport and partitioning in developing peach trees, Acta Horticulturae, 2002, 584: 29-34.

Michalski R.S., Davis J.H., Bisht V.S. and Sinclair J.B. PLANT/ds: an expert consulting system for the diagnosis of soybean diseases, Proc. European Conference on Artificial Intelligence, July, 1982, Orsay, France: 133-138.

Plant R.E., Zalom F.G., Young J.A. and Rice R.N. An expert system for the diagnosis of peach and nectarine disorders. HortScience, 1989, 24: 700.

Schreiber G. Shi Z.Z., Liang Y.Q., Wu B. et al (translated). Knowledge Engineering and Knowledge Management. China Machine Press, Beijing, 2003: 79-106 (in Chinese).

Wang J.H., Yang X.T., Wang B.H. The construction of the agricultural expert system knowledge database based on the HPC develop platform. Computer and agriculture, 2001 (4):13-16 (in Chinese).

Wang Y.A., Li M., Wang L.L. et al. The knowledge database construction of fruit trees expert system for diagnosis, prevention and control of disease and pest, Journal of Shandong agricultural university. 2005, 36: 475-480 (in Chinese).

$\mathrm{Xu}$ M.X. The Cultivation Technology of Fruit Trees in Drought Area. Jindun Publishing House, Beijing: 1998 (in Chinese). 